\title{
Edible Bird's Nest Extract Reduced Expression of Senescence Markers in Bone Marrow Mesenchymal Stem Cells
}

\author{
$\underline{\text { Lina Elfita*1,2 }}$, letje Wientarsih ${ }^{3}$, Dondin Sajuthi ${ }^{3}$, Indra Bachtiar ${ }^{4}$ \& Huda \\ Shalahudin Darusman ${ }^{5}$ \\ ${ }^{2}$ Graduate School of IPB University, Jl. Raya Dramaga, Bogor \\ ${ }^{2}$ Department of Pharmacy, Faculty of Health Science, Syarif Hidayatullah State Islamic University Jakarta, Banten \\ ${ }^{3}$ Department of Veterinary Clinic Reproduction and Pathology, Faculty of Veterinary Medicine, IPB University, Bogor \\ ${ }^{4}$ Stem Cell and Cancer Institute, Jl. Jend. Ahmad Yani Jl. Pulo Mas No.2, RT.3/RW.13, Kayu Putih, Kec. Pulo Gadung, Jakarta \\ ${ }^{5}$ Department of Anatomy, Physiology and Pharmacology, Faculty of Veterinary Medicine, IPB University, Bogor
}

\begin{abstract}
Edible bird's nest (EBN) is often consumed as a health food due to its suggested health benefits, including anti-aging effects, however the mechanism is still unknown. This study investigated the effect of EBN extract using long term expansion bone marrow-derived mesenchymal stem cells (BMMSCs) as an aging model. Passage 5 (P5) and passage 8 (P8) BMMSCs were treated with EBN extract, and their proliferation, senescence-associated $\beta$-galactosidase (SA- $\beta$-Gal) activity, and expression of p16 ${ }^{\text {INK4a }}$ were analyzed. Treatment of BMMSCs with EBN extract decreased population doubling time (PDT) in P5 but not in P8 BMMSCs. In P5 BMMSCs, 200 ppm EBN extract increased BMMSCs proliferation, with PDT reduced by 27.6\%. However, 200 ppm EBN extracts did not affect P8 BMMSCs proliferation, although it increased BMMSCs viability. Treatment of P5 and P8 BMMSCs with 200 ppm EBN extract decreased SA- $\beta$-Gal activity by $54.8 \%$ and $47.1 \%$ of the control, respectively $(P<0.05)$. Levels of p16 INk4a expression were 5.4-fold lower in P5 BMMSCs treated with $200 \mathrm{ppm}$ EBN extract compared to control $(P<0.05)$. Similarly, treatment of P8 BMMSCs with 200 ppm EBN extract reduced p16 INK4a mRNA level by 7.9 -fold compared to the control $(P<0.05)$. In order to investigate the pathway of EBN extract inhibition, we further analyzed IL-6 and NF-KB1 expression. Treatment of P5 and P8 BMMSCs with 200 ppm EBN extract reduced IL-6 mRNA levels by 7.9-fold and 2.1-fold of control, respectively $(P<0.05)$. We found that 200 ppm EBN extract reduced NF-KB1 mRNA level approximately 2.4-fold both in P5 and P8 BMMSCs (P<0.05). Thus, EBN extract reduces markers of senescence, indicated by decreased SA- $\beta$-Gal activity and p16 ${ }^{\text {INK4a }}$ mRNA level, and this correlated with reduced messenger RNA levels of the pro-inflammatory factor IL-6 and the transcription factor NF-kB1.
\end{abstract}

Keywords: edible bird's nest; mesencymal stem cell; aging; p16 ${ }^{\text {INK4a }}$; SA- $\beta$-Gal.

\section{Introduction}

Aging is a complex process characterized by accumulation of degenerative damage, including a progressive decline in stem cell function, resulting in less effective tissue homeostasis and repair. Stem cell exhaustion, which may driven by an imbalance of stem cell quiescence and proliferation, is one of the hallmarks of aging, in which is associated with age-related degenerative and proliferative diseases [1]. Age-related dysfunction of stem cells is caused by both cell-intrinsic and cell-extrinsic mechanism. Instrinsic mechanisms inlcude telomere dysfunction, DNA damage-induced cellular senescence, and age-related increases in the expression cell cycle inhibitors [2-3].

Previous studies reported that the $\mathrm{p} 16^{\mathrm{INK} 4 a}$ tumor suppressor gene plays a key role in cellular senescence in human cells. In addition, p16 $6^{\mathrm{INK} 4 \mathrm{a}}$ was identified as an inhibitor of the cell cycle kinases CDK4 and CDK6, allowing it to act as a tumor suppressor by negatively regulating the cell cycle. p16 $6^{\mathrm{INK} 4 \mathrm{a}}$ expression gradually increases with aging in most mammalian tissues [4]. Another study demonstrated that down regulation $\mathrm{p} 16^{\mathrm{INK} 4 \mathrm{a}}$ may slow down the aging process, and lead to rejuvenation of senescence [5]. Moreover, inhibition of $\mathrm{p} 16^{\mathrm{INK} 4 \mathrm{a}}$ may ameliorate the physiological impact of aging on stem cells and thereby improve injury repair in aged tissue [6]. Thus, there is a consensus that $\mathrm{p} 16^{\mathrm{INK} 4 a}$ expression is increased with age and is correlated with cellular senescence, thus $\mathrm{p} 16^{\mathrm{INK} 4 \mathrm{a}}$ appears to be a reliable biomarker for senescence.

It is also well known that

\section{Article history}

Received: 10 Nov 2020 Accepted: 27 Jan 2021 Published: 30 April 202

Access this article

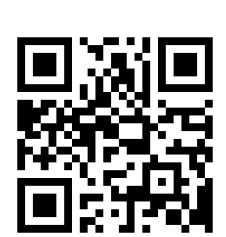


senescent cells are characterized by upregulation of many lysosomal proteins and increased lysosomal content. Senescent cells display an elevated senescence-associated $\beta$-galactosidase (SA- $\beta$-Gal) activity, and it remains the gold standard to identify lysosomal content of senescent cells in culture and tissue samples [7]. In addition, emerging evidence suggests that senescence causes a loss of tissue repair capacity because of cell cycle arrest in progenitor cells and senescence cells produce pro-inflammatory and matrix-degrading molecules in what is known as the senescence-associated secretory phenotype (SASP) [8]. The SASP includes secretion of different cytokines such as IL-6 and growth factors. The SASP and its associated molecules are powerful markers of senescence.

The availability of nutritional and Pharmacological agents that can target derangements in metabolism of senescent cells to improve stem cells function and regenerative potential provides an apportunity for new therapeutic strategy. Many compounds or extracts from natural products have been reported to slow aging and extend lifespan, but we are unaware of reports on the effects of edible bird's nest (EBN) on Cellular senescence.

EBN, which produced from the salivary secretions of Collocalia sp, is well-known for its high nutritional value and medicinal properties. Previous studies found that more than half of EBN's weight is consisted of protein, making EBN a good source of protein [9]. However, there is lack of scientific research to support the evidence-based use of EBN as supplement, particularly as an agent to interfere cellular senescence. Thus, in the present study, we investigated the effect of EBN extract and its mechanisms on cellular senescence by using bone marrow-derived mesenchymal stem cells (BMMSCs) as a model. Proliferation rates, viability, and cell senescence marker were quantified and compared among experimental group to examine the effect of EBN extract on BMMSCs senescence.

\section{Materials and Methods}

\section{Culture and Characterization of BMMSCs}

Human BMMSCs (obtained from Stem Cell and Cancer Institute, Jakarta) were seeded at an initial cell density of $4,000 \mathrm{cell} / \mathrm{cm}^{2}$ in $75-\mathrm{cm}^{2}$ tissue culture flask (Biologix, USA) and maintained at $37^{\circ} \mathrm{C}$ with $5 \% \mathrm{CO}_{2}$ in DMEM containing low-glucose levels (Gibco, USA) supplemented with 10\% fetal bovine serum (FBS; Gibco, USA) and $1 \%$ antibiotic-antimycotic (Gibco, USA). When cultures reached $70-80 \%$ confluence, cells were harvested and their numbers were counted. The cells were then washed in PBS, pH 7.4 and adjusted to $10^{6}$ cells. Monoclonal anti-CD73-PE, anti-CD90-PE, anti-CD104PE, anti-CD34-PE, anti-CD45-PE, anti-CD14-FITC and anti-HLA-DR-PE antibodies (Becton Dickenson, USA) were added into the cells and incubated for 30 min in the dark. After double washing in a CellWASH solution (Becton Dickenson, USA) the cells were fixed in FIX solution (Becton Dickenson, USA). The specific
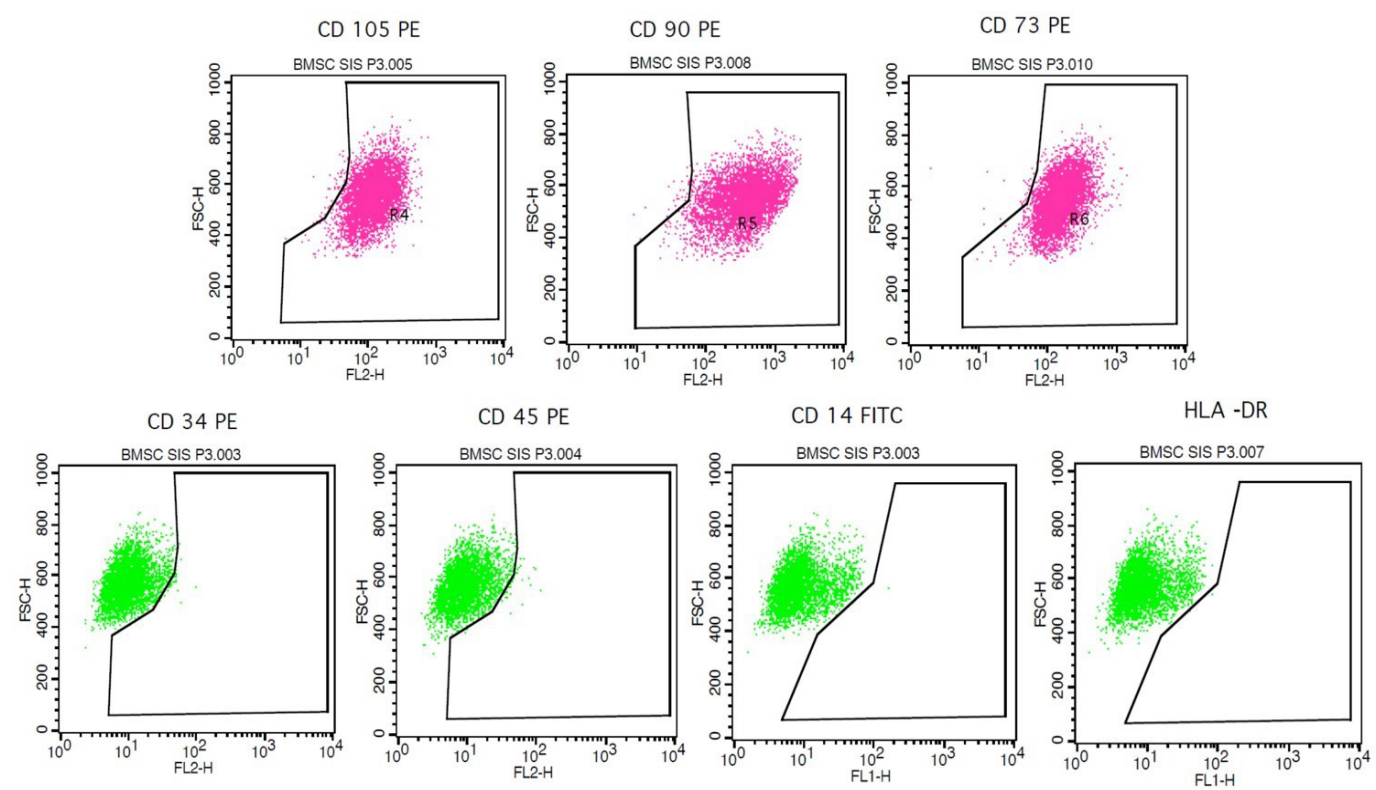

Figure 1. FACS analysis of BMMSCs 
P3

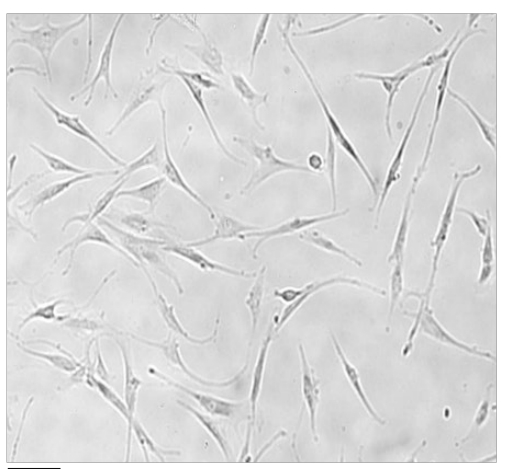

a

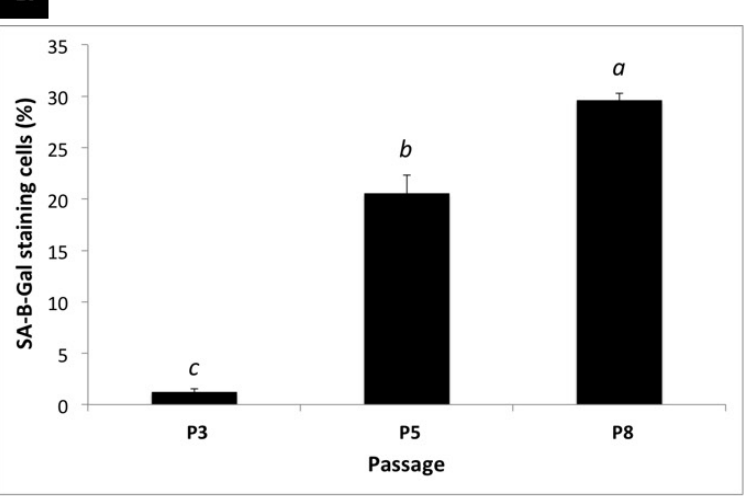

b

Figure 2. Representative images of senescence-associated $\beta$-galactosidase (SA- $\beta$-gal) staining of different passages (P3, P5 and P8) (a), quantitative analysis SA- $\beta$-gal staining of P3, P5 and P8 (b), and relative expression of p16INK4a mRNA of P3, P5 and P8 (c) of BMMSCs. a-c: different letter in each category means significantly different $(\mathrm{P}<0.05)$

fluorescent labeling was analyzed by FACSCalibur flow cytometer (Becton Dickenson, USA).

Preparation of EBN Extract and Treatment of BMMSCs with EBN Extract

Extraction of EBN (collected from Painan, West Sumatra, Indonesia) was performed according to previous methods with some modifications [10]. EBN was washed with 500 fold excess of water (w/v) three times and dried for $24 \mathrm{~h}$ at $37^{\circ} \mathrm{C}$, then was ground. The ground EBN was soak in sterile distilled water (1:50) and kept in water bath $\left(37^{\circ} \mathrm{C}\right)$ for $24 \mathrm{~h}$ and then filtered with Whatman 4 filter paper. The filtrate was dialyzed using a 3,500 Da cutoff membrane for $4 \mathrm{~h}$ and hydrolyzed with the bacterial peptidase subtilisin (Alcalase, Sigma, Germany) as a final concentration of $1 \%$ in water, at $60^{\circ} \mathrm{C}$ for $2 \mathrm{~h}$, and then heated at $100^{\circ} \mathrm{C}$ for $15 \mathrm{~min}$. The hydrolysate was then cooled down to room temperature and freeze dried. The extract stored at $4^{\circ} \mathrm{C}$ until use. Passage 5 (P5) of BMMSCs were treated with $50 \mathrm{ppm}$ and $200 \mathrm{ppm}$ EBN extracts,
P5

P8
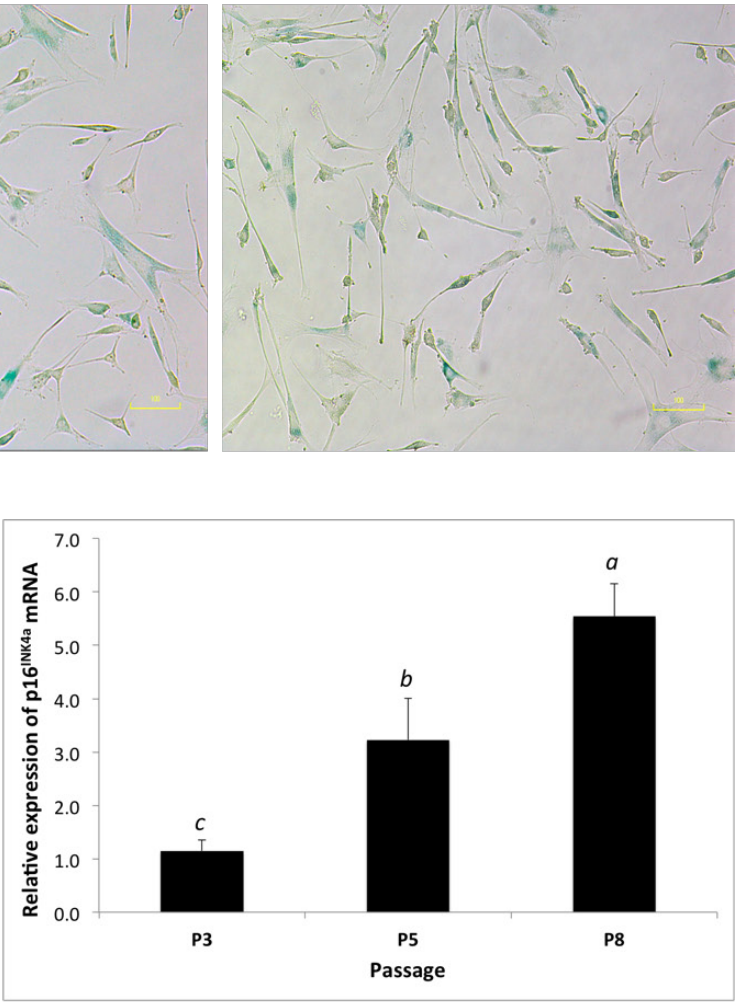

C 
Table 1. Proliferation rate and viability of BMMSCs

\begin{tabular}{|c|c|c|c|c|}
\hline Passage & Sample & Viability (\%) & PDT (day) & PDL \\
\hline \multirow{4}{*}{ P5 } & Control & $93.87 \pm 2.13 a$ & $7.03 \pm 0.59 a$ & $1.86 \pm 0.16 b$ \\
\hline & EGF & $94.37 \pm 0.58 a$ & $6.01 \pm 0.48 b$ & $2.17 \pm 0.18 b$ \\
\hline & EBN 50 ppm & $94.37 \pm 2.64 a$ & $6.40 \pm 0.21 a b$ & $2.03 \pm 0.07 b$ \\
\hline & EBN 200 ppm & $94.83 \pm 1.80 a$ & $5.09 \pm 0.51 c$ & $2.57 \pm 0.26 a$ \\
\hline \multirow{3}{*}{ P8 } & Control & $83.90 \pm 3.09 b$ & $11.16 \pm 1.12 b$ & $1.53 \pm 0.15 a$ \\
\hline & EGF & $78.89 \pm 2.10 b$ & $14.10 \pm 2.04 a b$ & $1.22 \pm 0.18 b$ \\
\hline & EBN 200 ppm & $93.00 \pm 3.02 a$ & $15.26 \pm 1.42 \mathrm{a}$ & $1.12 \pm 0.10 b$ \\
\hline
\end{tabular}

a-c: different letter in same column means significantly different $(P<0.05)$

Senescence- Associated $\beta$-Galactosidase (SA- $\beta-G a l)$ Assay

BMMSCs senescence was examined by staining for SA- $\beta-$ Gal by using the Senescence Cells Histochemical Staining Kit (Sigma, Germany). BMMSCs were plated at 15,000 cells $/ \mathrm{cm}^{2}$ in 24 well plates $(\mathrm{n}=3)$ and incubation for 24 hours at $37^{\circ} \mathrm{C}$ in humidified $5 \% \mathrm{CO}_{2}$ incubator. BMMSCs were washed 3 times with PBS and fixed the solution provided according to manufacturer's instruction. Plates were then stained with X-gal solution for 24 hours at $37^{\circ} \mathrm{C}$. The cells were visualized by phase contrast microscope, and the number of cells positive for SA- $\beta$ Gal activity versus total cells was quantified and imageJ software v.1.52. For each well, at least 200 cells from 3-6 images were counted to obtain percentages.

\section{Quantitative Real Time PCR Analysis}

Real-Time PCR was performed to determine the levels of p16 $6^{\mathrm{INK} 4 a}$, IL-6 and NF- $x$ B1 mRNA in BMMSCs after the different treatments. The total RNA of each sample was extracted and purified from whole cell lysates using the RNeasy Plus Mini Kit (Qiagen, Germany). The reverse transcription of $1 \mu \mathrm{g}$ of RNA to cDNA was established using cDNA Reverse Transcription kit (Applied Biosystems, USA). Quantitative PCR was performed on a StepOne Real-Time PCR system (Applied Biosystems, USA) by using TaqMan fast advanced master mix (Applied Biosystems, USA). All RT-PCR reagents, including primers and probes, were purchased from Applied Biosystems (Assay ID); p16 ${ }^{\mathrm{INK} 4 a}$ (Hs00923894_ m1); IL-6 (Hs00174131_m1); NF-xB (Hs00765730_m1). The gene glyceraldehyde-3-phosphate dehydrogenase $(\mathrm{GAPDH})$ was used as an internal control. The $2^{-\Delta \Delta C T}$ method was employed to normalize gene expression values prior to statistical analysis.

\section{Result and Discussion}

\section{Characterization of BMMSCs}

In order to chracterize BMMSCs used in this study, flowcytometry analysis was performed. The results showed that BMMSCs were positive for CD73, CD90 and CD105, and negative for CD14, CD34, CD45 and HLADR (Figure 1), indicating that BMMSCs were fulfilled the criteria as a mesenchymal stem cell (MSC) based on The International Society for Cellular Therapy (ISCT).

\section{Long-term in Vitro Expansion of BMMSCs}

We first investigated the process of cellular senescence of BMMSCs during long term in vitro expansion by measuring of SA- $\beta-$ Gal activity (Figure 2). SA- $\beta$-Gal stained cells were rare in P3 (approximately 1.3\% of cells), but SA- $\beta$-Gal activity significantly increased to approximately $20.5 \%$ and $30.0 \%$ of cells in P5 and P8 respectively. Similarly, the expression level of $\mathrm{p} 16^{\mathrm{INK} 4 \mathrm{a}}$ was also increased approximately 3.1-fold and 4.8-fold in P5 and P8 BMMSCs, respectively, compared to P1.

Senescent cells display an elevated senescenceassociated $\beta$-galactosidase (SA- $\beta$-Gal) activity, and it remains the gold standard to identify lysosomal content of senescent cells in culture and tissue samples [7]. Sumilarly, p16 ${ }^{\mathrm{INK} 4 \mathrm{a}}$ expression is reported to gradually increase with aging in most mammalian tissues [4]. Moreover, the use of p16 $6^{\text {INK4a }}$ reporter mice in several models of senescence and aging demonstrated that the appearance of cells in their tissues positive for SA- $\beta-$ Gal is associated with elevated proportion of $\mathrm{p} 16^{\mathrm{INK} 4 \mathrm{a}}$-expressing cells [12]. Concordant with these, our data showed that SA- $\beta-$ Gal activity and p16 ${ }^{\mathrm{INK} 4 a}$ expression increased in senescent P5 and P8 BMMSCs (Figure 2b, 2c). Thus, our results confirmed that 


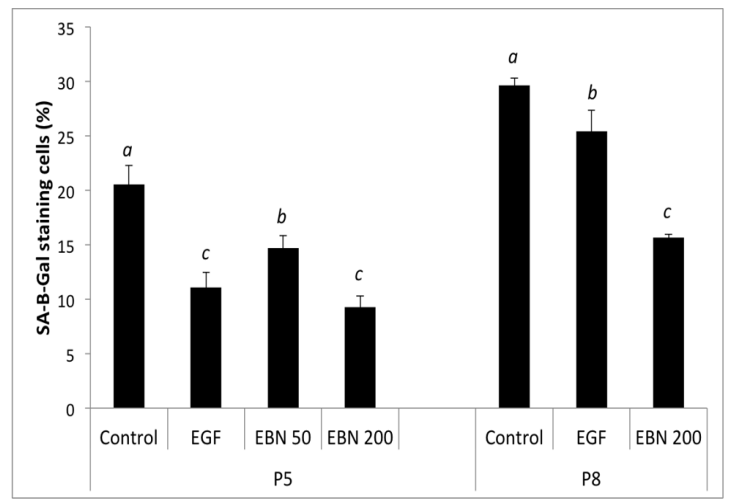

a

Figure 3. Effect of EBN extracts on SA- $\beta-G a l$ activity (a) and gene expression of p16INK4A (b). a-d: different letter in each category means significantly different $(\mathrm{P}<0.05)$

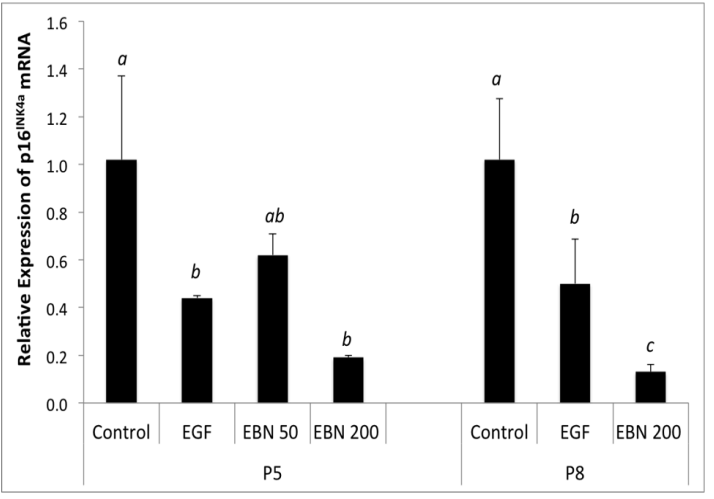

b
P5 and P8 BMMSCs were indeed undergoing a senescence process, in which P5 and P8 BMMSCs were categorized as early and late passage of BMMSCs, respectively, and both P5 and P8 BMMSCs were used in the entire study.

\section{Effect of EBN Extract on Senescent BMMSCs} Viability, PDT and PDL

The effect of EBN extracts on BMMSCs viability, PDT and PDL were shown in Table 1. EBN extracts, at any concentration, did not significantly improved P5 BMMSCs viability, but EBN extract at 200 ppm increased P8 BMMSCs by about $10.9 \%$ compared to the control. Low PDT and high PDL indicate increased cell proliferation. As expected, the overall PDT of P5 BMMSCs were lower than that of P8 BMMSCs, and overall PDL of P5 BMMSCs were higher than that of P8 BMMSCs. These results confirmed that the capability of BMMSCs to proliferate was decreased along with passage number. Treatment of BMMSCs with EBN extract, as well as EGF, decreased PDT and increased PDL in P5, but not in P8. In P5 BMMSCs, EBN (200 ppm) and EGF treatment increased BMMSCs proliferation, evidenced by decrease in PDT by as much as $27.6 \%$ and $14.5 \%$, respectively. On the other hand, EBN extracts (200 ppm) did not affect P8 BMMSCs proliferation, although it increased viability of BMMSCs compared to non-treated P8 These results indicated that EBN extract had different effects on BMMSCs, depending on the stage of cell senescence.

A previous study demonstrated that EBN extract promoted proliferation of human adipose-derived stem cells (hADSCs) through increased expression of IL-6 and VEGF genes, mediated by activation of transciption factor $\mathrm{NF}-x \mathrm{~B}$ [10]. This is concordance with our finding in which EBN extract promoted proliferation of P5 BMMSCs, which are in a relatively early phase of senescence. However, in late phase of BMMSCs senescence, the effect was not observed. It has been known that senescent cells secrete an altered mix of factors into their environment [13]. It is suggested that in late phase of senescence, the secreation of those factors increase significantly, and these interfere with the effect of EBN extract on P8 BMMSCs. However, further investigation is needed to elucidate the detail mechanism of action of EBN extract on proliferation of senescent BMMSCs.

EBN Extract Decreased SA- $\beta-G a l$ Activity and Levels of $\mathrm{p} 16^{\mathrm{INK} 4 \mathrm{a}}$ in Senescent BMMSCs

Analysis of senescence at the cellular level was carried out by measuring SA- $\beta-G a l$ enzyme activity. In P5, treatment of BMMSCs with EBN extracts as well as EGF showed a significant decrease in SA- $\beta-$ Gal activity compared to control (Figure 3a). Treatment of P5 BMMSCs with $50 \mathrm{ppm}$ and $200 \mathrm{ppm}$ EBN extract decreased SA- $\beta$-Gal activity by approximately $28.6 \%$ and $54.8 \%$ respectively, compared to the control, indicating that the effect of EBN extract on SA- $\beta-G a l$ activity was dose-dependent. Similarly, treatment of P8 BMMSCs with 200 ppm EBN extract decreased the SA- $\beta$-Gal activity by approximately $47.1 \%$ compared to the control $(\mathrm{P}<0.05)$.

We also analyzed expression of $\mathrm{p} 16^{\mathrm{INK} 4 \mathrm{a}}$, a well known marker of senescence. Consistent with SA- $\beta$-Gal activity, as shown in Figure $3 \mathrm{~b}, \mathrm{p} 16^{\mathrm{INK} 4 \mathrm{a}} \mathrm{mRNA}$ level was decreased by approximately 80\% in P5 BMMSCs treated with $200 \mathrm{ppm}$ EBN extract compared to control $(\mathrm{P}<0.05)$. Treatment of P5 BMMSCs with 50 ppm EBN extract caused only a slight decrease in $\mathrm{p} 16^{\mathrm{INK} 4 \mathrm{a}} \mathrm{mRNA}$ level, indicating the effect of EBN extracts on $16^{\text {INK4a }} \mathrm{mRNA}$ level was also dose-dependent. Similarly, treatment of P8 BMMSCs 


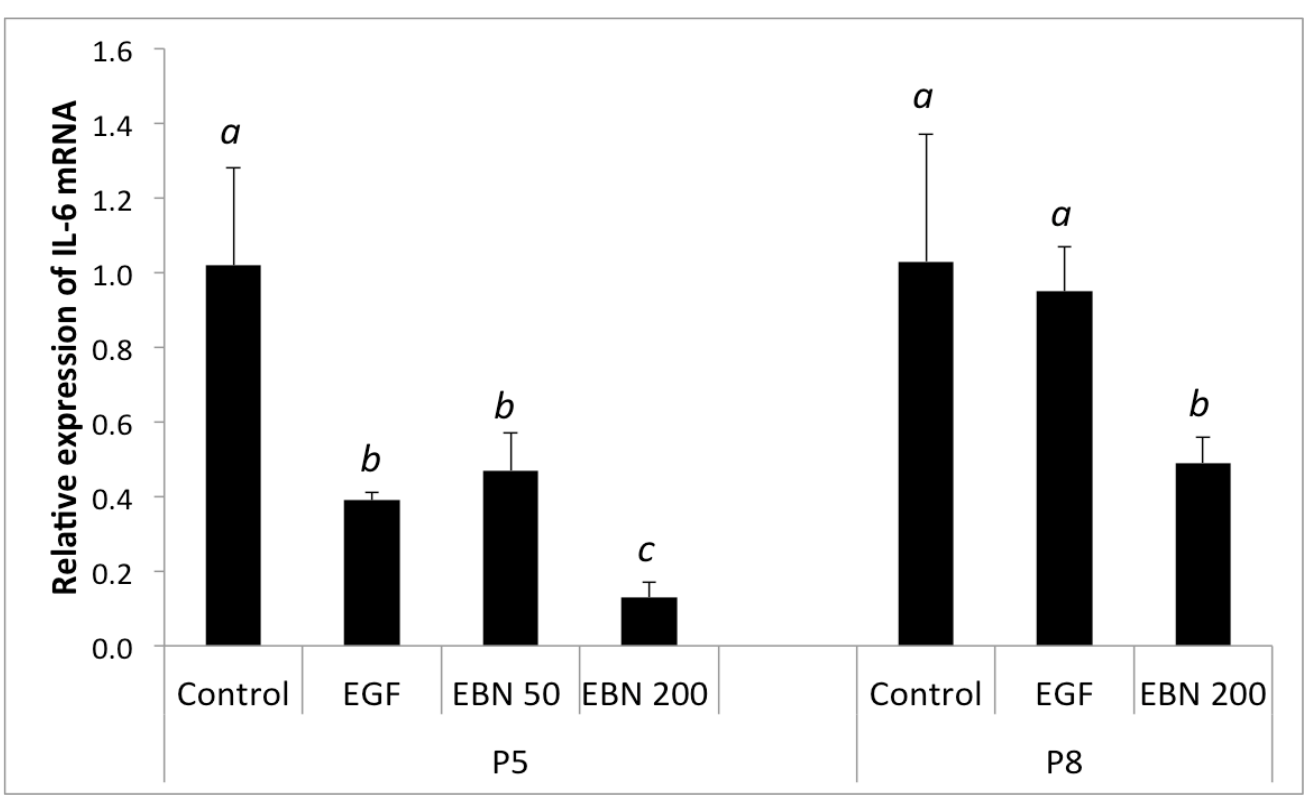

Figure 4. Effect of EBN extracts on gene expression of IL-6. a-c: different letter in each category means significantly different $(\mathrm{P}<0.05)$

with 200 ppm EBN extract decreased the mRNA level of p16 $6^{\text {INK4a }}$ to approximately $12 \%$ of the control $(\mathrm{P}<0.05)$. Both the SA- $\beta-$ Gal activity and the reduction of $\mathrm{p} 16^{\mathrm{INK} 4 \mathrm{a}}$ expression indicate that, like EGF, EBN extract was able to reduce cell senescence of BMMSCs during long-term in vitro expansion.

$\mathrm{p} 16^{\mathrm{INK} 4 \mathrm{~A}}$ is an important player in the regulation of cell senescence. One of $\mathrm{p} 16^{\mathrm{INK} 4 \mathrm{~A}}$, $\mathrm{s}$ major functions is to act as a cyclin-dependent kinase inhibitor (CKI) by binding to and inhibiting cyclin-dependent kinases (CDKs) 4 and 6 [14]. Over time, mass inhibition of the cell cycle causes cycle arrest and therefore senescence. Senescent cells that show elevated $\mathrm{p} 16^{\mathrm{INK} 4 \mathrm{~A}}$ expression eventually lose ability to proliferate and cell population growth is halted [15]. Through its cell cycle inhibition effects, p16 $6^{\mathrm{INK} 4 \mathrm{~A}}$ has also proven itself to be a major regulator of self-renewal of various stem cell types [16]. It has been shown that silencing of $\mathrm{p} 16^{\mathrm{INK} 4 \mathrm{~A}}$ could increase hematopoietic stem cell proliferation and transplant efficacy [17]. Another study also demonstrated that to attempt a reversal of cell cycle arrest, knockdown of $\mathrm{p} 16^{\mathrm{INK} 4 \mathrm{~A}}$ by lentiviral infection encourage the progenitor cells to enter cell division, increase cell proliferation, and lead to an overall increase in cell survival [5]. Concordant with this findings, our study demonstrated that EBN extract downregulated the expression of cell cycle inhibitor $\mathrm{p} 16^{\mathrm{INK} 4 \mathrm{~A}}$ in senescent BMMSCs and allowed progression of the cell cycle and eventually increased the proliferation of senescent BMMSCs (Table 1).
EBN Extract Reduced IL-6 Gene Expression in Senescent BMMSCs

Since SASP is strongly associated with senescence in stem cells, we also investigated the effect of EBN extract on the expression of IL-6, one of the major SASP associated cytokines, in order to elucidate a possible mechanism by which EBN extract could reduce senescence of BMMSCs. As shown in Figure 4, the expression level of IL-6 was decreased by when BMMSCs were treated with EBN extract, both in P5 and P8 cells. In P5, treatment of BMMSCs with 50 ppm and 200 ppm EBN extract downregulated the expression of IL-6 approximately 2.2-fold and 7.9-fold, respectively $(\mathrm{P}<0.05)$. In addition, treatment of P8 BMMSCs with 200 ppm EBN extract also resulted in approximately 2.1-fold reduction of IL- 6 mRNA level compared to control $(\mathrm{P}<0.05)$. These results demonstrated that EBN extract also inhibited the expression of IL-6, not only in P5 but also in P8 BMMSCs.

It is known that SASP is associated with increased expression of chemokines and cytokines such as IL-6 and IL-8 [18]. Both in vivo and in vitro studies have documented that IL-6 has been shown in senescent cells. It has been shown that increased serum levels of pro-inflammatory cytokines, including IL-6, in aged individuals as compared to young individuals [19]. Gene expression analysis by microarray in human hepatic stellate cells confirms that replicative senescence in these cells is associated with a pronounced inflammatory phenotype characterized by upregulation of pro-inflammatory cytokines, including 


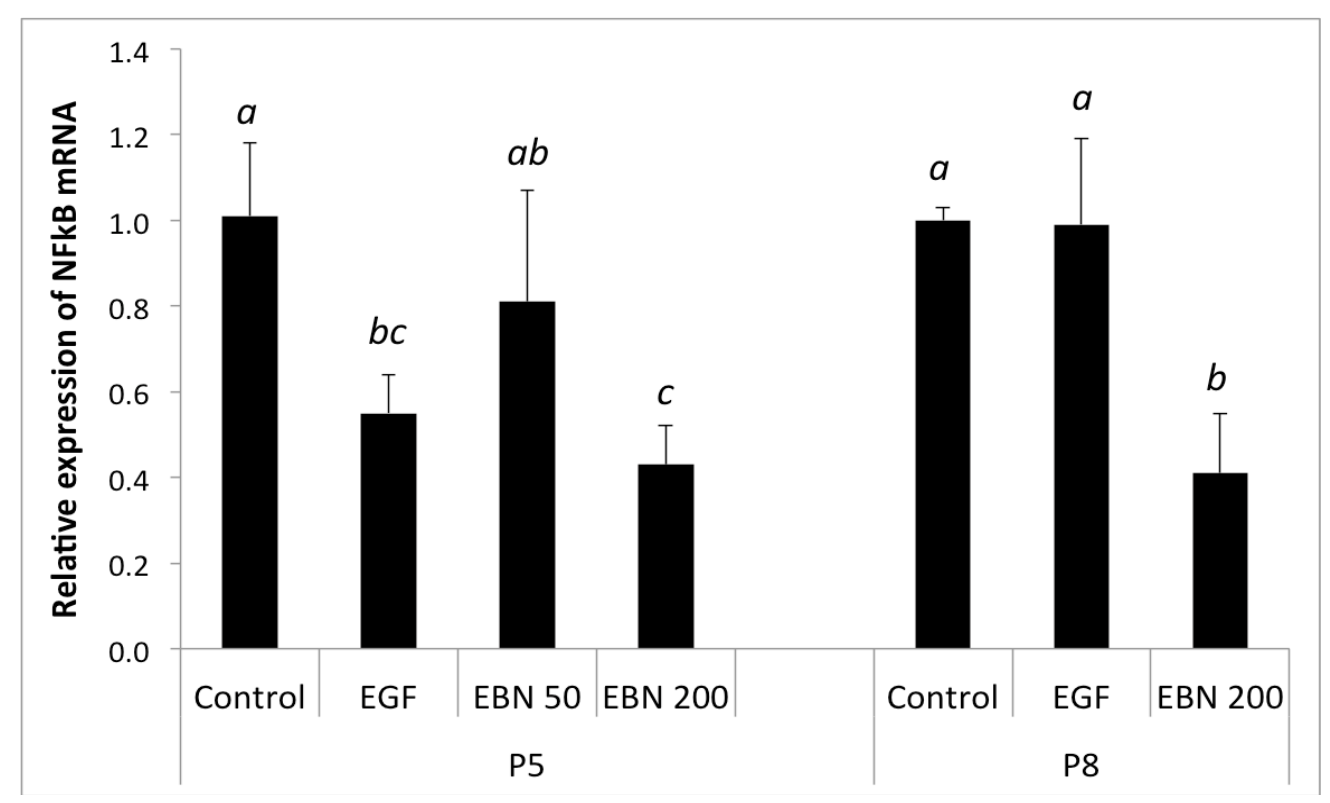

Figure 5. Effect of EBN extracts on gene expression of NF- $x$ B1. a-c: different letter in each category means significantly different $(\mathrm{P}<0.05)$

IL-6 and IL-8 [20]. In senescent cells, IL-6 is suggested to reinforce senescence-associated proliferation arrest of untransformed primary cells in a cell-autonomous autocrine manner [21]. Thus, IL-6 is an important marker in senescent cells, which prompted us to analyze the effect of EBN extract on expression of IL-6. We found that EBN extract inhibited IL-6 expression both in early stage (P5) and late stage (P8) of senescence of BMMSCs.

NF-кB signaling is involved in inhibition of IL-6 gene expression in senescent BMMSCs

$\mathrm{NF}-x \mathrm{~B}$ as a transcription factor regulates a variety of cellular genes that are important in the maintenance of cellular physiology. To elucidate the involvement of NF- $x \mathrm{~B}$ in EBN extract-reduced expression of IL-6, the expression level of NF- $x$ B1 was measured. We found that $200 \mathrm{ppm}$ EBN extract reduced NF- $x$ B1 mRNA level approximately 2.4-fold both in P5 and P8 BMMSCs (P<0.05) (Figure 5). On the other hand, 20 ppm EBN extract reduced NF$x \mathrm{~B}$ expression in P5 BMMSCs by approximately 1.3-fold, however the effect was not statistically significant. These results suggest that transcription factor $\mathrm{NF}-\varkappa \mathrm{B}$ signaling may affected down-regulation of IL-6 expression.

The expression of IL-6 is controlled at multiple levels. Several factors have been described as regulators of IL-6 mRNA either at transcriptional or post-transcriptional level. The IL- 6 promoter contains motifs for the binding of many transcirption factors including NF- $x \mathrm{~B}$ [22]. Many investigations exhibited that NF-kB functions as a central transcription factor by turning on pro-inflammatory mediators including IL-6, for the development of chronic inflammatory diseases [20]. Several studies demonstrated an increase in constitutive NF- $x \mathrm{~B}$ DNA binding in older animals over young animals. For instance, age-dependent elevation in NF-xB DNA binding has been reported in mouse and rat liver and heart and in rat brain indicating a potential involvement of $\mathrm{NF}-x \mathrm{~B}$ in regulating agingassociated chronic inflammation [23-24]. These studies indicates strong correlation between transcription factor NF- $x$ B, IL-6 expression and senescence. Since our data demonstrated that EBN extract also decreased NF-kB1 expression in P5 and P8 BMMSCs, the reduction of IL-6 mRNA levels may be associated with down-regulation of NF- $x \mathrm{~B} 1$ expression. However, since NF- $x \mathrm{~B}$ signaling is a complex process involving many molecules, further investigation is needed to elucidate the mechanism.

\section{Conclusion}

We demonstrated that EBN extract significantly downregulated (SA- $\beta-\mathrm{Gal}$ ) activity and the expression of $\mathrm{p} 16^{\mathrm{INK} 4 \mathrm{a}}$ in P5 and P8 BMMSCs, indicating that EBN extract could act as anti-aging. Since EBN extract inhibited the expression of IL- 6 and transcription factor NF-kB in both P5 and P8 BMMSCs, it is suggested that the mechansim of anti-aging of EBN extract is through inhibition of transcription factor NF-kB which control the expression of pro-inflammatory mediator IL-6. This 
study also suggested that EBN extract could be useful as a nutraceutical and has development potential as an antiaging medicine. However, further in vivo study should be carried out to demonstrate the property of EBN extract as anti-aging.

\section{Acknowledgement}

The authors thank Dr. David Vaux (Walter and Eliza Hall Institute of Medical Research, Australia) for critical reading of the manuscript.

\section{References}

[1]. Oh J., Lee YD., Wagers AJ. Stem cell aging: Mechanism, regulators and theraoeutic opportunities. Nat Med. 2014;20:870-880. doi: https://doi.org/10.1038/nm.3651.

[2]. Gunes C, Rudolph KL. The role of telomeres in stem cells and cancer. Cell. 2013;152:390-393. doi: https://doi.org/10.1016/j. cell.2013.01.010.

[3]. Jones DL, Rando TA. Emerging models and paradigms for stem cell ageing. Nat Cell Biol. 2011;13:506-512. doi: 10.1038/ncb0511-506.

[4]. Yu KR, Kang KS. Aging-related genes in mesenchymal stem cells: A Mini-Review. Gerontology. 2013;59:557-563. doi: https://doi. org/10.1159/000353857.

[5]. Khatiwala RV, Zhang S, Li X, Devejian N, Bennet E, Cai C. Inhibition of p16INK4a to Rejuvenate Aging Human Cardiac Progenitor Cells via the Upregulation of Anti-Oxidant and NFKB Signal Pathways. Stem Cell Rev Rep. 2018 Aug;14(4):612-625. doi: https://doi. org/10.1007/s12015-018-9815-z.

[6]. Janzen V, Forkert R, Fleming HE, Saito Y, Waring MT, et al. Stem-cell ageing modified by the cyclin-dependent kinase inhibitor p16INK4a. Nature. 2006;443:421-426. doi: https://doi.org/10.1038/ nature05159.

[7]. Debacq-Chainiaux F, Erusalimsky JD, Campisi J, Toussaint O. Protocols to detect senescence-associated beta-galactosidase (SAbeta-gal) activity, a biomarker of senescent cells in culture and in vivo. Nat Protoc. 2009;4:1798-1806. doi: https://doi.org/10.1038/ nprot.2009.191.

[8]. Childs BG, Durik M, Baker DJ, Deursen JMV. Cellular senescence in aging and age-related disease: from mechanisms to therapy. Nat Med. 2015;21:1424-1435. doi: https://doi.org/10.1038/nm.4000.

[9]. Elfita L, Wientarsih I, Sajuthi D, Bachtiar I, Darusman HS. The diversity in nutritional profile of farmed edible bird's nest from several regions in Indonesia. Biodiversitas. 2020;21:2362-2368. doi: https://doi. org $/ 10.13057 /$ biodiv/d210604

[10]. Roh KB, Lee J, Kim YS, Park J, Kim JH, et al. 2012. Mechanism of edible bird's nest extract-induced proliferation of human adipose-derived stem cells. Evid Based Complementary Alternat Med. 2012. doi: https://doi.org/10.1155/2012/797520.
[11]. Alexander PB, Yuan L, Yang P, Sun T, Chen R, et al. EGF promotes mammalian cell growth by suppressing cellular senescence. Cell Res. 2015;25:135-138. doi: https://doi.org/10.1038/cr.2014.141.

[12]. Hall BM, BalanV, Gleiberman AS, Strom E, Krasnov P, et al. p16(Ink4a) and senescence-associated $\beta$-galactosidase can be induced in macrophages as part of a reversible response to physiological stimuli. Aging. 2017;9:1867-1884. doi: https://doi.org/10.18632/ aging. 101268 .

[13]. Adams PD. Healing and Hurting: Molecular mechanisms, functions, and pathologies of cellular senescence. Mol Cell. 2009;36:2-14. doi: https://doi.org/10.1016/j.molcel.2009.09.021.

[14]. Hara E, Smith R, Parry D, Tahara H, Stone S, Peters G. Regulation of p16CDKN2 expression and its implications for cell immortalization and senescence. Mol Cell Biol. 1996;16:859-867. doi: https://doi. org/10.1128/mcb.16.3.859.

[15]. Baker D, Childs B, Durik M, Wijers ME, Sieben CJ, et al. Naturally occurring p16Ink4a-positive cells shorten healthy lifespan. Nature. 2016;530:184-189. doi: https://doi.org/10.1038/nature16932.

[16]. D'Arcangelo D, Tinaburri L, Dellambra E. The Role of p16INK4a pathway in human epidermal stem cell self-renewal, aging and cancer. Int J Mol Sci. 2017;18:1-30. doi: https://doi.org/10.3390/ ijms18071591.

[17]. Stepanova M, Rodriguez E, Birerdinc A, Baranova A. Age-independent rise of inflammatory scores may contribute to accelerated aging in multi-morbidity. Oncotarget. 2015; 6:1414-1421. doi: https://doi. org/10.18632/oncotarget.2725.

[18]. Coppé J-P, Desprez P-Y, Krtolica A, Campisi J. The SenescenceAssociated secretory phenotype: The dark side of tumor suppression. Ann Rev Pathol. 2010;5:99-118. doi: https://doi.org/10.1146/ annurev-pathol-121808-102144.

[19]. Bruunsgaard H, Pedersen M, Pedersen BK. Aging and proinflammatory cytokines. Curr Opin Hematol. 2001;8:131-136. doi: https://doi.org/10.1097/00062752-200105000-00001.

[20]. Sarkar D, Fisher PB. Molecular mechanisms of aging-associated inflammation. Cancer Lett. 2006;236:13-23. doi: https://doi. org/10.1016/j.canlet.2005.04.009.

[21]. Acosta JC, O'Loghlen A, Banito A, Guijarro MV, Augert A, Raguz S. Chemokine signaling via the CXCR2 receptor reinforces Senescence. Cell. 2008;133:1006-1018. doi: https://doi.org/10.1016/j. cell.2008.03.038.

[22]. Spooren A, Kooijman R, Lintermans B, van Craenenbroeck K, Vermeulen $L$, et al. Cooperation of NFKB and CREB to induce synergistic IL-6 expression in astrocytes. Cell Signal. 2010;22:871881. doi: https://doi.org/10.1016/i.cellsig.2010.01.018.

[23]. Helenius M, Hanninen M, Lehtinen SK, Salminen A. Aging-induced up-regulation of nuclear binding activities of oxidative stress responsive NF-kB transcription factor in mouse cardiac muscle. J Mol Cell Cardiol. 1996;28:487-498. doi: https://doi.org/10.1006/ imcc.1996.0045.

[24]. Korhonen P, Helenius M, Salminen A. Age-related changes in the regulation of transcription factor NF-kappa B in rat brain. Neurosci Lett. 1997;225:61-64. doi: https://doi.org/10.1016/s03043940(97)00190-0. 